\title{
TRAZOS DE UNA EDUCACIÓN HEDONISTA
}

TRAITS OF HEDONISTIC EDUCATION

TRAÇOS DE UMA EDUCAÇÃO HEDONISTA

Iván Darío Uribe ${ }^{\star}$, Luz Elena Gallo**, Alexandre Fernández Vaz ${ }^{\star \star \star}$

Palabras clave: Educación.

Cuerpo.

Enseñanza.

Placer.

Keywords:

Education.

Body.

Teaching.

Pleasure.

Palavras-chave Educação.

Corpo.

Ensino.

Prazer.
Resumen: El objetivo de esta investigación es articular el hedonismo a una reflexión educativa teniendo como marco analítico al cuerpo. Se acude a un análisis sobre el concepto de hedonismo en la tradición filosófica, observando su carácter polifónico: hedonismo ascético, libertario, utilitarista, solar y vitalista. A partir de ello, se delinean algunos trazos que constituyen una Educación Hedonista como aquella que se asienta en una razón corporalizada, que sitúa al cuerpo en la fuerza del instante, realiza el arte de vivir, trae la risa, se rige por el deseo y enaltece el juego.

Abstract: This research relates hedonism to educational reflection as a framework for looking into the body. It analyses the concept of hedonism in the philosophical tradition and finds that it has a polyphonic character: ascetic, libertarian, utilitarian, solar, and vitalistic hedonism. From there, it points out some traits that constitute Hedonistic Education as based on embodied reason; it places the body in the strength of the moment; it realizes the art of living; it brings up laughter; it is based on desire; it exalts play.

Resumo: A presente pesquisa tem como objetivo articular o hedonismo a uma reflexão educativa, tendo o corpo como marco analítico. Estabelece-se uma análise sobre 0 conceito de hedonismo na tradição filosófica, observando-se seu caráter polifônico: hedonismo ascético, libertário, utilitarista, solar e vitalista. A partir disso, são delineados alguns traços que constituem uma Educação Hedonista como aquela que se assenta em uma razão corporalizada, que situa o corpo na força do instante, realizando a arte de viver, traz o riso, rege-se pelo desejo e enaltece o jogo.
*Universidad de Antioquia. Medellín, Colômbia.

E-mail: ivan.uribe@udea.edu.co

**Universidad de Antioquia-Colombia, Medellín, Colômbia.

E-mail: luz.gallo@udea.edu.co

***Universidade Federal de Santa Catarina (UFSC). Florianópolis, SC Brasil.

E-mail: alexfvaz@uol.com.br

Recebido em: 28-09-2016 Aprovado em: 22-01-2017

(c) (i) () Licence 


\section{INTRODUCCIÓN ${ }^{1}$}

El objeto de esta investigación teórica es delinear trazos de una Educación Hedonista cuyo marco de análisis es el cuerpo. ¿Qué hay entre las palabras hedonismo, educación y cuerpo? Cuando hacemos el ejercicio de reflexionar qué hay en medio de ellas, nos ponemos en el lugar de las relaciones. En el concepto de hedonismo se puede encontrar lúdica, placer, deseo, goce, alegría, felicidad, voluptuosidad, imaginación, fascinación, voluntad de goce, arte de vivir, ética y estética de la existencia (NIETZSCHE, 2001; CRUZ, 2013; ONFRAY, 2007,

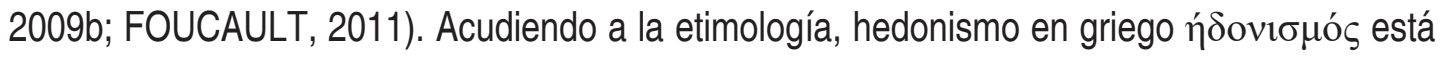

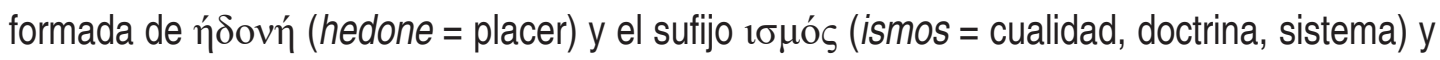
significa placer, gozo, voluptuosidad, "el hedonismo hace referencia a una filosofía del placer entendido como el consentimiento de un cuerpo al eudemonismo (a la felicidad) que lo requiere" (ONFRAY, 1999, p. 227). ¿Dónde está la felicidad?, está en la potencia de un cuerpo que goza y en un querer que proporciona satisfacción a uno mismo y al otro - ética (ONFRAY, 2009a).

Epicuro, creador de una de las primeras escuelas que ven al placer como un objeto de estudio en relación con la vida misma, nos dice que los placeres que provienen del pensamiento, de un estado de la mente y del alma tienen privilegio sobre los placeres corporales -la comida, la bebida, la sexualidad, el movimiento-, pero, también nos dice que tanto el alma como la carne son existencias materiales, es decir, corpóreas. El cuerpo piensa como realidad encarnada, la carne piensa y el cuerpo reflexiona; esa unión de cuerpo y alma está dotada de vida, movilidad, sensaciones y afecciones; el placer está encarnado en nuestra sensibilidad, los placeres básicos son los de nuestros sentidos corporales, los de la carne.

Las últimas reflexiones estéticas de autores como Nietzsche, Michel Foucault y, contemporáneamente, Michel Onfray proponen nuevas ideas para pensar una educación hedonista teniendo en cuenta el gusto, el cotidiano, lo sensible, entre otros. De hecho, Nietzsche, Foucault y Onfray ponen el hedonismo en una perspectiva ética. Conceptos como la ética del placer, el arte de vivir, el cuidado de sí y del otro, el uso de los placeres y hacer de la vida una obra de arte ponen al cuerpo en un primer lugar. Michel Onfray (2014), refiriéndose a las ciudanías rebeldes en los tempos de hoy, plantea la necesidad de pensar en unas pedagogías del placer, en una educación que suponga un contrato ético y construir una educación a partir de lo que somos capaces con el cuerpo.

Hurgando por las presencias del hedonismo en la educación encontramos una predominancia de lo intelectivo sobre lo sensible; la educación moderna ha dejado por fuera los placeres y el deseo; la educación se instala en una razón descorporalizada; los discursos se dirigen más a la inmaterialidad de una "mente" que al cuerpo "vivido"; la educación se dedica poco a enseñar y aprender en el placer; la risa y el goce tienen poca presencia en la clase; se exalta una formación en valores como la prudencia y la mesura; el juego se usa básicamente cómo medio para enseñar un contenido (REISBERG, 2008; MÉNDEZ, 2010; FLORES, 2010). A su vez, encontramos estudios que, sin pretensiones dicotómicas, pretenden pensar una educación más allá de racionalidades instrumentales e intentan poner la corporalidad en la educación sin dualismos reductivos y que ponen el cuerpo como lugar de la experiencia educativa (GALLO; MARTÍNEZ, 2015; WENETZ; DORNELLES, 2012; CASTRO; FARINA, 2015).

1 El presente artículo forma parte de la investigación de tesis doctoral "El hedonismo en clave educativa" y del proyecto "Didácticas de la Educación Corporal: El buen arte de la preparación de la clase". 
Aunque la mayoría de los estudios acerca del hedonismo tratan sobre el juego, el pasatiempo y la diversión, algunos autores se preguntan si "¿es posible educar estimulando la fascinación, la admiración, la fantasía, la creatividad, el placer? ¿O estamos condenados a seguir educando a partir de certezas inamovibles y de preconcepciones homogenizantes?" (MÉNDEZ, 2010, p. 24). Con la misma inquietud, Flores (2010, p. 41) recomienda "[...] transitar de la repetición acrítica de contenidos, a la generación de aprendizajes placenteros [...] buscar alternativas para una educación que supere el paradigma tradicional, lleva a la necesidad de promover una auténtica participación gozosa". Reisberg (2008) propone una educación ligada a los placeres estimulando la enseñanza y el aprendizaje a través de recursos lúdicos y estéticos. Hay un reclamo por una educación lúdica que pase por los placeres, la experiencia y el deseo (GIL, 2013); y Dalla y Bufrem (2013) enfatizan en el papel del profesor como responsable en provocar condiciones pedagógicas para el placer, la autonomía y la creatividad.

Para delinear trazos de una Educación Hedonista, se hizo necesario reconocer el concepto de hedonismo en la tradición filosófica tomando como base la obra del filósofo francés Michel Onfray (1959- ), quien hace un estudio del hedonismo en la filosofía antigua (Cirenaicos, Cínicos y Estoicos), en el período helenístico (Epicúreos), en la ilustración (empiristas y utilitaristas) y en algunos filósofos con ideas contra-hegemónicas de los siglos XIX y XX como Nietzsche y Foucault, a partir de allí, encontramos un carácter polifónico en el concepto de hedonismo el cual podemos describir como hedonismo ascético, libertario, utilitarista, solar y vitalista.

Por su parte el hedonismo ascético se caracteriza por la prudencia y la moderación, estos administran los placeres, evitan dolores y su interés es lograr serenidad y felicidad. Para el hedonismo libertario las características están en lo erótico, lo voluptuoso, en gozar lo que acontece en el instante, en la celebración de lo corporal y su complacencia en la medida en que no traiga consecuencias para el sufrimiento y la libertad. En el hedonismo utilitarista los modos de conseguir la felicidad radican en la utilidad común y en lo colectivo. El hedonismo solar y vitalista está ligado al cuerpo, a lo sensible, a los placeres corporales, es un cuerpo que desea el goce, un cuerpo que ama la vida con pasión e intensidad y disfruta el placer de existir; este hedonismo está enraizado en una ética y una estética de la existencia.

\section{LECTURAS DEL HEDONISMO EN CLAVE EDUCATIVA}

\section{Trazo 1. Una Educación hedonista se asienta en una razón corporizada.}

Uno de los elementos comunes que atraviesa las ideas del hedonismo es el cálculo de los placeres. Desde Epicuro se establece cierto cálculo para ponderar el mayor placer y el menor dolor en toda actividad, lo esencial es saber elegir y rechazar ciertos deseos, placeres y dolores en forma adecuada para lograr una vida placentera; aquí la sabiduría emana de la inmanente racionalidad de lo corporal.

Helvecio acoge, enaltece y pondera los sentidos y las pasiones. Las pasiones y los deseos nos mueven y se constituyen en el impulso de nuestras acciones, en los motivos de ser y existir; sin las pasiones desaparece el deseo y la razón misma de la existencia, cuando uno deja de ser apasionado no hay ningún motivo para el mismo impulso y crecimiento de la razón, pues las sensaciones y las pasiones son causa y principio del deseo y el entusiasmo para 
emprender cualquier ideal o proyecto. Una razón corporizada, "informa de qué son el placer y el dolor, el bien y el mal, la felicidad y la desdicha, las percepciones agradables o desagradables, queridas o detestadas" (ONFRAY, 2010, p. 157).

En el hedonismo ascético el uso moderado de los placeres que operan entre la mesura y la prudencia se constituyen en un modo de vida. En la adecuada regulación de los placeres reside la posibilidad de llegar a conquistar la autonomía y la autarquía para saber discernir sobre lo más conveniente o no y, con ello, llegar a conquistar la aponía y la ataraxia, es decir, la tranquilidad, la serenidad y el equilibrio de ánimo. En el hedonismo vitalista también hay una clara preocupación por delimitar el uso que se le da a los placeres en el sentido de ocuparse de sí (como el arte de la relación del individuo con su propio cuerpo-razón corporizada). Se trata de una cierta preocupación dietética, que a decir de Foucault (2011) es como una especie de medicina para las existencias, de aquellas prácticas que usa el sujeto para darse forma, para constituirse como un sujeto y, en ello, reside la capacidad para ejercer (o no) un dominio y control de sí mismo, esto es, al mismo tiempo, "un ejercicio de -askësis- de existencia" (FOUCAULT, 2011). En clave educativa son también las maneras como cada persona va tomándose forma a sí mismo y se va constituyendo como sujeto.

Desde el hedonismo Epicureísta hasta el Vitalista prevalece la mesura, el equilibrio y el cálculo en el uso de los placeres, se desechan goces que puedan ocasionar algún daño a sí mismo y a otros, o aquellos placeres que generan dependencia y, específicamente los epicúreos, convocan a la prudencia buscando como producto la serenidad entendida como ausencia de dolor y turbación. "Se trata de un hedonismo domesticado, razonado y razonable, de una cordura que, apuntando al placer como objetivo último, se encamina hacia la eudaimonía por una senda ascética y calculada" (GARCÍA, 2002, p. 193).

\section{Trazo 2. Una Educación hedonista sitúa el cuerpo en la fuerza del instante.}

En el hedonismo libertario y vitalista se exalta la dimensión del tiempo, es un tiempo que nos pone en el lugar de la presencia del aquí y el ahora como una forma de no dejar escapar el presente y hacer presente el cuerpo con experiencias que implican prestar atención a lo que nos pasa, lo que nos afecta y que entraña ciertos aprendizajes. Así como una educación que pase porque la persona se haga presente en lo que piensa, en lo que siente, en lo que desea (BÁRCENA, 2012).

Una educación hedonista nos pone a pensar cómo situar los cuerpos en este instante, en el aquí y el ahora, cómo hacemos durar el instante como intensidad. El instante es el aión de los griegos, es la dimensión puntual del tiempo, la intensidad de un momento que no se puede medir cronológicamente, es el tiempo de la infancia, lo dice Heráclito en el fragmento 52 el tiempo, aión, es un niño que juega. El tiempo de la educación ha sido más la cronología que el instante y el hedonismo libertario sugiere recuperar "una pedagogía del instante" en el sentido del encuentro del aquí y el ahora para que se hagan presentes los cuerpos en el aula -no sólo intelectivamente- así, el aula podría constituirse en un espacio vital e intensivo donde confluyan afecciones. Este trazo nos dice de la necesidad de pensar en los ambientes de enseñanza, educar es también ofrecer signos hedonistas que intenten establecer relación con la vida misma, por ejemplo, los hedonistas nos sugieren el compartir la palabra a través del arte de la conversación. 
Si bien el tiempo del instante es el tiempo de la infancia, una educación hedonista podría hacer presente el "instante" en lo educativo como tiempo y espacio de libertad, imaginación, fantasía, novedad, asombro, curiosidad. Una "Pedagogía del Instante" habita el presente en la acción y el movimiento, exalta el cuerpo vivido que se complace con el riesgo, la observancia, la voluptuosidad, la risa, los goces y placeres. Su fuerza son todas las relaciones inclinadas a la pulsión de vida; su método es el trayecto, el encuentro, la conversación. Su contenido aquello que genera novedad, movimiento y transformación. Su objeto y fin la amistad, la empatía, el afecto, el buen trato, la deferencia, la cordialidad, la afinidad, los placeres, la voluntad de goce, la alegría, la prudencia, la sensatez, la celebración de la existencia, la mayor felicidad posible como finalidad de la vida.

Una Educación hedonista que sitúe el cuerpo en la fuerza del instante implica hacer resonancia con "lo que es o está presente" en los escenarios educativos, aquello que se hace tangible, lo que hacemos aparecer, lo que se produce o se torna visible, audible, táctil, kinestésico; también con las maneras como nos hacemos presentes en nuestro tiempo. Estar presente en algo es también prestar atención y estar atentos a lo que nos pasa en el escenario educativo y a las maneras como nos hacemos visibles y hacemos visibles los cuerpos.

\section{Trazo 3. Una Educación hedonista realza el arte de vivir.}

Si bien desde la filosofía griega el placer se relacionó con la "vida tranquila", quizás fueron Demócrito de Adbera pensador del siglo V y Epicuro de Samos filósofo del siglo IV a.C, quienes trataron el tema del placer con la moral cuya clave consiste en discernir qué placeres se deben buscar y cuáles evitar de cara a una buena vida (ONFRAY, 2012). La vida hedonista sería un modo de vida que se corresponde con la tranquilidad del ánimo, buen estado emocional, estar-bien, el goce moderado y la usencia de excesos, sin embargo, como la vida humana se construye de diversas formas, el hedonismo no constituye ningún modo de vida "general o universal"; es decir, cada uno ha de desarrollar el propio arte de vivir.

Saber del mundo, es fundamentalmente, un saber de sí lo cual se vuelve coextensivo con la vida, con el arte de vivir guiado por la moderación, la prudencia y el uso de una libertad racional en la búsqueda de la autonomía y la autarquía; disposiciones para discernir sobre lo conveniente o no de las acciones en el gobierno de sí mismo y, con ello, lograr la serenidad y equilibrio de ánimo. La clave está en no dañar ni ser dañado como principio que funda la comunidad humana, condición básica para vivir virtuosamente, es decir, placentera, juiciosa, honesta y justamente.

En las ideas del hedonismo en Nietzsche, Foucault y Onfray, el placer está enraizado en el cuerpo y en desear experiencias de placer. La finalidad de toda vida humana está anclada en un hedonismo solar que significa gozar de vivir, querer vivir una vida feliz (tranquila), una vida abrigada e instaurada en los placeres vitales, en los placeres que traen alegría a los cuerpos y que aumentan su potencia de obrar, por tanto, hay que procurar evitar las pasiones tristes, los sufrimientos y la disminución de la potencia de obrar de los cuerpos.

En las fuerzas dionisiacas hay toda una simbología corporal de la boca, el rostro, de la palabra, del baile; así como la embriaguez, la pasión, el canto, la danza son expresiones dionisiacas que apuntan hacia lo trasgresor, lo ilimitado más allá de cualquier mesura; en Dionisio habita la felicidad, el eros ligero, la libertad, la voluptuosidad, la fecundidad, las intensidades, 
las potencias de la voluntad, el deseo y el amor a la vida como cambio constante, dinamismo, movimiento perpetuo y la transformación; disposiciones que suponen modificaciones en el equilibrio y la armonía del individuo y de la realidad, ocasionadas en el choque delirante con las potencias de la embriaguez que habitan nuestro espíritu dionisíaco y que son contenidas por Apolo en la obra educadora de la cultura: el orden, la discreción, la cautela, el tacto y la moderación. En Dionisio vive la potencia que habita el individuo que no ha domesticado la vida con sus hábitos y costumbres, porque sabe y conoce que la vida va más allá y es más fuerte que él mismo. Dejarse habitar por el hedonismo vitalista supone apertura a oportunidades para la construcción, formación y educación del individuo como una obra de arte, una bella individualidad, un sujeto singular (ONFRAY, 2016; NIETZSCHE, 2001).

Hacia finales del siglo XX y comienzos del siglo XXI, Michel Foucault y, actualmente, Michel Onfray con su proyecto de la filosofía hedonista, sitúan el hedonismo en el territorio de una ética y estética de la existencia. En un estudio histórico y crítico se analizan "las prácticas mediante las cuales los individuos se vieron llevados a prestarse atención a ellos mismos, a descubrirse, a reconocerse y a declararse como sujetos de deseo" (FOUCAULT, 2011, p. 11). Conceptos como los placeres, el cuidado sí, del otro y el hacer de la vida una obra de arte constituyen un "Arte de vivir" coextenso con la inquietud de sí y con la vida individual y se ubica en el momento en que los jóvenes dejan de estar en manos de los "pedagogos" y entran a la vida.

Una ética hedonista supone atención al goce propio, al mismo tiempo, que al del otro $\mathrm{y}$, en virtud de las lógicas que mueven al ser humano en la búsqueda del goce, los placeres y la satisfacción de los deseos, se requiere acudir a una intersubjetividad contractual o contrato ético en la que se compartan por igual esfuerzos, voluntades, goces, placeres y displaceres. Una ética de los placeres está vinculada con una ética hedonista, cuyo principio estableció Chamfort en una de sus máximas: "goza y haz gozar, sin hacer daño a nadie ni a ti mismo: ésa es la moral" (ONFRAY, 1999, p. 226).

Una ética del placer vincula el cuerpo a la felicidad. En el hedonismo libertario es vital la búsqueda de los lugares de la felicidad y, para ello, es necesario situar el placer en un marco del goce ético, el placer trasciende la mera satisfacción de los sentidos, el seguir los impulsos salvajes y naturales y consentir aquello que nos asemeja a la bestia (violencia, astucia, hipocresía). Unas pedagogías del placer suponen un contrato ético, de allí, la necesidad de pensar la ética por la vía de la educación (ONFRAY, 2012).

\section{Trazo 4. Una Educación hedonista trae la risa.}

Para el hedonismo vitalista, la risa se convierte en un recurso simbólico de respuesta al carácter trágico y displacentero de la existencia. En el hedonismo vitalista de Nietzsche hay una relación de la risa como "consuelo intramundano" en el que Dionisio aparece como espíritu libre ligero, leve y humano; con su risa aparece una forma reacción, afirmación, liberación y exaltamiento de la vida. La risa es una especie de armadura que protege, es signo de transgresión, insolencia, alegría, también nos libra momentáneamente de la necesidad, de las finalidades, de lo absurdo, del sinsentido, del hastío, de las contradicciones; y también es señal de un pensamiento capaz de experimentar lúdicamente. 
Para el hedonismo vitalista y solar, reírse es de espíritus libres, de personas capaces de trascenderse a sí mismos. De ahí que la risa se constituya en una figura estética para pensar lo educativo en estos tiempos que educar se erige por saberes serios y rígidos, que proporciona seguridad y nos hace creer que todo tiene una finalidad, un sentido y un orden, y que el pensamiento está ligado a la seriedad. Una educación hedonista no ha de perder la risa ni el humor pues esto acerca a un pensamiento creador, a un saber alegre, necesitamos una educación traviesa, lúdica, deseante, flotante, bailarina, burlesca, infantil y alegre. Una educación que valore el reírse, que se aventure a la vida jugando y riendo, que se afirme en la copertenencia existente entre placer y displacer (entretejido entre lo apolíneo y lo dionisiaco), unidad ambivalente y ambigua como consecuencia de su inseparabilidad. La risa expresa tanto lo contradictorio como el acuerdo.

\section{Trazo 5. Una Educación hedonista se rige por el deseo.}

En el hedonismo, la idea de deseo no siempre está asociado con el placer, en ocasiones, deseos y placeres se enfrentan como procesos de singularización, formación de subjetividades, dimensiones constitutivas del ser y como categorías de poder (DELEUZE, 2006). Para el hedonismo ascético algunos deseos apetitivos pulsionales o instintivo y racionales son, a la vez, placeres; en el hedonismo vitalista Foucault habla del uso de los "placeres" en la distribución que de ellos hacemos, es la fuerza que asocia entre sí actos, placeres y deseos; y con Deleuze los "deseos" no implican falta o carencia, no son producto de una determinación natural ni espontánea, son flujos, procesos y acontecimiento; con Nietzsche el deseo está relacionado con la voluntad, y para el hedonismo utilitario con la acción orientada a un fin.

Si bien para el hedonismo algunos deseos producen placeres en tanto atienden a lo inmediato, al presente y no aplazan su objetivo, hay otros deseos que requieren edificarse o construirse, para el hedonismo vitalista el deseo no es algo natural, no es, no existe, no hay que satisfacerlo, gracias a la voluntad, el deseo tiene que crearse y formarse, hay que agenciarlo, de allí que el deseo es potencia y placer en vía de desarrollo. Así pues, hay que esculpir el propio deseo como se hace con el barro, la madera, el cartón, el bronce, el hierro y el material bruto en una escultura; hay que pulir los deseos, preparar los deseos con dedicación, cuidado, atención y con voluntad; no hay que creer que el deseo basta para obtener un placer 0 proporcionar bienestar, no hay que creer que la satisfacción vulgar, pura y simple de un deseo es suficiente para construirse así mismo sin antes haber labrado, sin haber creado, hecho 0 inventado el camino. Hay que dejar que un deseo se haga grande, que aumente su potencia, en términos nietzscheanos, es dejar que la fuerza pulsional llegue hasta su límite.

Para la educación, el deseo es producción y creación, no es algo que deba surgir de manera espontánea o naturalizada, de allí, que podamos pensar que el deseo en una educación hedonista implica ponerse a disposición, dis-ponerse al encuentro, disponerse a lo que viene. Una educación que ofrezca elementos que sean "deseables" o proporcione ambientes para pensar, sentir, actuar; que recupere el deseo de enseñar y aprender; que los encuentros educativos sean un lugar para amplificar, multiplicar y aumentar las capacidades y las potencias de obrar de cada cuerpo menos homogénea y más diversificada. Esta forma de educar exige hacer resonancia con "el desear" como acceso a nuevas potencias; tal vez educar sea también devenir placer en el acto de enseñar y aprender. 


\section{Trazo 6. Una Educación hedonista enaltece el juego.}

El juego en el hedonismo vitalista y solar encuentra una forma de respuesta a una actividad humana que no se guía por la finalidad, la verdad o la racionalidad, pues el juego es un escenario del "crear" que expresa incertidumbre, riesgo, lucha, contienda, sosiego, oscilación, fluctuación, vibración y, por el otro lado, es pasión, emoción, energía, embriaguez y desenfreno. El hedonismo vitalista de Nietzsche se vale de la figura del juego en tanto constituye una forma suprema y valiosa de relación del ser humano con el mundo en la que puede verse una actividad humana libre, espontánea, de fantasía e imaginación, referente de una actividad humana creadora, gozosa y de potenciación de la fuerza vital.

Para el hedonismo, el juego se constituye a veces como una actividad estética en tanto acción creadora y en una actividad lúdica, así como el niño que convierte el juego en una actividad tanto creadora y artística, como de disfrute y goce. Aunque en el juego encontramos como referencia la expresión griega del agón o impulso agonal entendido como impulso competitivo y de rivalidad, en el vitalismo nitzscheano el juego pasa a ser un principio estético en términos de la posibilidad de crear y, como el juego es sin "porqué", lo que importa en la experiencia del juego es que la acción se halla en su propio acontecer "en la que algo está en juego".

El juego es presencia de lo no previsible en lo previsible, de lo incógnito y lo no explicable, es posibilidad de creación y suscita formas sin formas, lógicas en las no lógicas, el juego es el florecer de lo espontáneo y lo incierto como efervescencia de flujos y reflujos, viaje en el tiempo, riesgo, irregularidad, es lo inadvertido y fortuito del azar, lo repentino y sorprendente de lo no esperado, lo no pensado y lo no sospechado, es duda y vacilación, perplejidad en lo supuesto, de la seriedad en la informalidad, es la sorpresa, lo súbito, drástico, radical, cruel y fulminante. El juego es apertura a la incertidumbre, estallidos de exuberancia en el instante, acción, movimiento y relación que se manifiesta en cualquier momento, es la irrupción y el salto entre momentos de discontinuidades; el juego es expresión de libertad, ligereza, abundancia y voluntad de querer. "El juego es una especie de alarde de fuerza: en medio del "claroscuro" de la vida cotidiana, lanza un reto al sosegado estancamiento del mundo" (DUVIGNAUD, 1980, p. 152).

En la educación el juego ha de hacer presencia como experiencia en la acción porque es condición de posibilidad para que el ser humano viva y se manifieste en experiencias que comprenden acciones lúdicas, expresiones voluntarias y manifestaciones espontáneas; relaciones, encuentros y conexiones durante las cuales quien juega vive la realidad del juego mismo en su totalidad. De este modo, el juego se configura en motivación deleite y fundamento que enaltece la educación, e igualmente una educación hedonista enaltece el juego para hacer de él posibles experiencias de formación.

\section{CONSIDERACIONES FINALES}

En la educación de los cuerpos hay presencias del hedonismo ascético que se instalan en la prudencia y la moderación, tal vez, la pregunta es si con ello se evitan dolores y se logra serenidad y felicidad. Una educación ascética opta por la abstención de los placeres del cuerpo, renuncia a la comicidad, la risa, la gracia, la alegría, la curiosidad. En esta educación 
se encuentra la premisa de la discretio, moderación, discreción y privación. Esta forma de educación tiende a la domesticación, el orden en la que la escuela se convierte en un espacio disciplinario como espacio parcelado que se organiza según reglas de distribución homogénea, estándar, vigilante, clasificatoria, reguladora, así una educación ascética se ocupa de disciplinar los cuerpos y como resultado se pretende la fabricación de cuerpos dóciles.

Del hedonismo libertario es posible pensar una propuesta pedagógica que se enfoque en recuperar el instante en la cual se piense en un tipo de pedagogía del aquí y el ahora, momento de presencias y existencias en un tiempo del aión, de una intensidad posible para los encuentros educativos que pase por experiencias lúdicas y placenteras, y relaciones entre saber y vida. A su vez este hedonismo nos sitúa próximos al cuerpo y, asintiendo que el cuerpo es el lugar de la experiencia, aspiramos suscitar una educación en relación con los placeres atravesados por la emoción y la pasión, lo sensible, la atención, la conversación para una educación que, desde un estar juntos, provoque afecciones en lo que nos pasa o acontece en el instante; que nos ponga en situación de incertidumbre, novedad y perplejidad; que consienta y motive la invención, la improvisación y el descubrimiento de otros sentidos de las cosas que hacemos en la vida y en el aula (CONTRERAS, 2013).

Para pensar una educación hedonista es vital tener un marco de goce ético, una educación que suponga un contrato ético. Una ética del placer, del cuidado de sí y del otro que apunta al arte de vivir. De algún modo, la idea será comprender el hedonismo ligado al cuerpo porque bien dice Onfray que la felicidad está en el cuerpo. Una ética hedonista supone primero un saber de nosotros y a los otros porque el hedonismo es atención al goce propio, al mismo tiempo, que al del otro. El contrato ético reside en ese movimiento que oscila de uno a otro (ONFRAY, 2009, p. 146).

En el hedonismo solar y vitalista que se rodea de la estética de la existencia y el arte de vivir, lo educativo está ligado con una ética de la mesura, ética que no se guía por lenguajes normativos, normas o convenciones, sino como arte de la medida, una actitud de conducción a uno mismo que proporciona a la existencia una forma de vida bella y singular. Este hedonismo resalta para lo educativo un énfasis por la moderación que aparece como forma estética y no una exigencia normativa.

Ante la preocupación por las condiciones hedonistas en la educación, este estudio cuestiona la predominancia de los placeres intelectivos en detrimento de la corporalidad y deja abierta la necesidad de pensar unas pedagogías del placer que se acentúen en el cuerpo sin dualismo reductivos en una dirección ética y estética que, en versión dionisiaca, haga del aula un lugar para la "experimentación corporal" ¿Será posible pensar una Educación Corporal que no trate sólo de cosas, sino de acontecimientos y experiencias que pongan en juego los placeres? ¿Podremos hablar de unas didácticas "corporales" que se establecen en la pasión, en la emoción, en los afectos, en un espíritu de simpatía, en el entusiasmo, en la sutileza, en el contrato ético y en la inquietud de sí?, y que tensione la relación teoría y práctica que resulta bastante incómoda para pensar hoy el cuerpo en la educación. ¿Por qué es incómoda?

Frente a una visión de la educación moderna que se dirige hacia lo razonable y estrecha lo sensible, el placer y el deseo; que se instala en una razón descorporalizada; que se dedica poco a enseñar y aprender en el placer; que se instala en un hedonismo ascetismo de control y negación de los placeres; que hace promesas de libertad y felicidad; y se interesa por seres humanos que calculen, controlen y mesuren el uso de los placeres, se hace necesario pensar 
una educación que tenga como finalidad el placer, la lúdica y el goce de vivir; que el saber (con el) que enseñamos puede sostenerse en un saber de la experiencia que pase por el cuerpo.

Reconocemos la necesidad de pensar el hedonismo en contextos de enseñanza. A la idea de educación como modelación, normalización, instrucción y disciplinamiento el hedonismo trae una idea de educar ligada a la experiencia como cualidad de lo que se vive, de acontecimientos que estén situados en un tiempo "vivido", en vivencias ancladas a lo que conmueve esa vivencia y al sentido de las cosas que remueve y al reconocimiento de sentimientos y razones no disociados. A las ideas de cuerpo disciplinado, fabricado, dócil, moldeado, entrenado, domesticado, corregido y desarrollado el hedonismo le aporta a una educación del cuerpo simbólico, sensible, que experimenta, descubre, vivencia y percibe. A las formas aprendizaje basadas en técnicas y competencias el hedonismo abre la posibilidad de aprender de manera placentera, como potenciación y rescate de las singularidades.

Reconocemos que los lenguajes de la educación del cuerpo están llenos de palabras traducidas por lógicas de la dominación, lo que nos lleva a plantear algunos rasgos hedonistas para pensar la educación por los afectos, por el instante, por el gusto y por el deseo, una educación de los placeres que prefiera más la (trans)formación y menos la instrucción. Por ello, reconocemos la importancia que hoy le da Michel Onfray a una ética hedonista como estética de la existencia y otros autores del denominado giro estético como Friedrich Nietzsche, Michel Foucault, Gilles Deleuze que abren la posibilidad de articular el hedonismo la educación teniendo como núcleo de análisis los cuerpos.

\section{REFERÊNCIAS}

BÁRCENA, Fernando. Una pedagogía de la presencia. crítica filosófica de la impostura pedagógica.

Teoría de la Educación, v. 24, n. 2, p. 25-57, 2012.

CASTRO, Julia; FARINA, Cynthia. Hacia un cuerpo de la experiencia en la educación corporal.

Revista Brasileira de Ciências do Esporte, v. 37, n. 2, p. 179-184, abr.jun. 2015.

CONTRERAS, José. El saber de la experiencia en la formación inicial del profesorado. Revista Interuniversitaria de Formación del Profesorado, n. 78, p. 125-136, 2013.

CRUZ, Manuel. Hedoné Aristóteles y el placer. Navarra: Ediciones Universidad de Navarra, 2013.

DALLA, Elisa; BUFREM Leilah. Aluno-Autor: a aprendizagem da escrita literária nas séries iniciais do ensino fundamental. Educação em Revista, v. 29, n. 1, p. 179-203, mar. 2013.

DELEUZE, Gilles. Deseo y placer. Traducción de Silvia N. Barei. Córdoba: Alción, 2006.

DUVIGNAUD, Jean. El juego del juego. Bogotá: Fondo de Cultura Económica, 1980.

FLORES, Luz. El placer de aprender. Revista Electrónica Educare, v. 14, p. 41-47, nov. 2010. Número extraordinario.

FOUCAULT, Michel. Historia de la sexualidad: el uso de los placeres. Traducción Martí Soler. Madrid: Siglo XXI, 2011. 
GALLO, Luz E.; MARTíNEZ, Leidy. Linhas pedagógicas para educação corporal. Cadernos de Pesquisa, v. 45, n. 157, p. 612-629, jul./set. 2015.

GARCÍA, Carlos. Epicuro: clásicos de Grecia y Roma. Madrid: Alianza, 2002.

GIL, Julio. La Lúdica en la Educación Corporal a partir de los conceptos de Experiencia y

Deseo. (Trabajo de investigación para Optar el título de Magister en Motricidad-Desarrollo Humano). Universidad de Antioquia, Medellín, 2013. CD Rom.

MÉNDEZ, Mario. El placer de aprender. Aportes para una pedagogía erótica. Diálogos, v. 4, n. 6, p. 21- 40, 2010.

NIETZSCHE, Friedrich. Así habló Zaratustra. Traducción de Andrés Sánchez Pascual. Madrid: Alianza, 2009.

NIETZSCHE, Friedrich. La gaya ciencia. Traducción de José Carlos Domingo. Madrid: Akal, 2001.

ONFRAY, Michel. El cristianismo hedonista: contrahistoria de la filosofía II. Traducción de Marco Aurelio Galmarini. Barcelona: Anagrama, 2007.

ONFRAY, Michel. Ciudadanías rebeldes en los tiempos de hoy. [Vídeo]. 2014. Disponible en: $<$ <ttps://www.youtube.com/watch?v=4CNIAkACJ1k>_Acceso en: 5 jul. 2016.

ONFRAY, Michel. El deseo de ser un volcán: diario hedonista. Traducción de Silvia Kot. Buenos Aires: Bitácora, 1999.

ONFRAY, Michel. La escultura de sí: por una moral estética. Traducción de Irene Antón. Madrid: Errata Nature, 2009a.

ONFRAY, Michel. Filósofo aquí y ahora. [Vídeo]. 2016. Disponible en: <https://www.youtube.com/ watch?v=WHKCoflf9n8 $>$. Acceso en: 27 ago. 2016.

ONFRAY, Michel. La fuerza de existir: Manifiesto hedonista. Traducción de Luz Freire. Barcelona: Anagrama, 2008.

ONFRAY, Michel. Los libertinos barrocos: contrahistoria de la filosofía, III. Traducción de Marco Aurelio Galmarini. Barcelona: Anagrama, 2009b.

ONFRAY, Michel. La risa de Demócrito. [Vídeo]. 2012. Disponible en: <https://www.youtube.com/ watch?v=PWxcUby7Wgcrisa de Demócrito>. Acceso en: 5 dic. 2016.

ONFRAY, Michel. Los ultras de las Luces: contrahistoria de la filosofía, IV. Traducción de Marco Aurelio Galmarini. Barcelona: Anagrama, 2010.

REISBERG, Mira. Social/ecological caring with multicultural picture books: Placing pleasure in art education. Studies in Art Education, a journal of issues and research in art education, v. 49, n. 3, p. 251-262, Spring 2008.

WENETZ, Ileana; DORNELLES, Priscila. Das articulações entre corpo e educação física: pistas para pensar. Cadernos CEDES, v. 32, n. 87, p. 247-248, maio/ago. 2012. 


\section{Apoio financeiro:}

CODI-Universidad de Antioquia, Colômbia. 